\title{
IMMUNISATION CENSUS OF THE 1992 SCHOOL INTAKE IN CENTRAL AND SOUTHERN SYDNEY
}

Kerrie Goldston, Mark Bek and Clare Nixon, Central and Southern Sydney Public Health Units.

†ए his report presents results of an immunisation survey ('census') of all children starting infant school (Kindergarten, Year 1, Year 2) in the Central and Southern Sydney Health Areas. The census was conducted by the Public Health Unit for Central and Southern Sydney in collaboration with the community health services of each Area, after a request from the NSW Health Department.

An aim of the census was to provide baseline information for use in evaluation of the Public Health (Amendment) Act, 1992. This Act seeks to increase childhood immunisation rates by requiring parents to provide documented evidence of a child's immunisation status on enrolment to all childcare centres, pre-schools and schools from 1994.

An important limitation of the data presented in this report, however, is that they are based only on parental recall. The accuracy of this information is unknown. Parents from nonEnglish speaking backgrounds, in particular, have often been found by the PHU to be unsure of their children's vaccination history.

\section{METHODS}

Data collection for the census was undertaken by child health nurses (CHNs), who traditionally collect information on immunisation together with other health information on children when they start school.

\section{Southern Sydney (Canterbury, St George and} Sutherland districts)

The PHU provided a survey form to CHNs in the Southern Sydney Area for entering summary data for each school in their area. This was returned to the PHU for collation.

Information on follow-up action for those children with inadequate immunisation histories was also provided by the CHNs working in the Sutherland and Canterbury districts.

The St George district employed a different system which did not provide information on non-kindergarten children or follow-up activities.

\section{Central Sydney}

CHNs also collected data using the form provided by the PHU. The community health service employed a computer system at RPAH to collate and analyse the data collected by CHNs, and has forwarded some results to the PHU. Unfortunately, due to technical difficulties with the system, many of the data were in error or missing and could not be interpreted.

\section{RESULTS}

\section{Southern Sydney}

Table 10 shows the proportion of children starting school in 1992 who were fully immunised (i.e. 4 x DTP, 4 x OPV, $1 \times$ MMR or MM, $1 \times$ CDT) in each of the three districts of Southern Sydney. Follow-up action by the CHNs resulted in another 3-5 per cent becoming fully immunised in the Sutherland and Canterbury districts.

Table 11 shows the same results for only those children starting kindergarten.

\section{Central Sydney}

Unfortunately there is much missing data from the Central Sydney Area. Table 12 shows what information is available for both kindergarten starters and all school starters.
TABLE 10

1992 CENSUS RESULTS FOR INFANT SCHOOL STARTERS IN THE SOUTHERN SYDNEY AREA

\begin{tabular}{|lrrrr|}
\hline District & \multicolumn{2}{c}{$\begin{array}{c}\text { No. No. children } \\
\text { schools } \\
\text { surveyed }\end{array}$} & $\begin{array}{c}\text { No. } \\
\text { fully } \\
\text { immunised } \\
\text { children } \\
\text { surveyed immunised (\%) }\end{array}$ & $\begin{array}{r}\text { Proportion } \\
\text { fully }\end{array}$ \\
\hline Canterbury & 24 & 2,925 & 3,484 & 84.0 \\
St George $^{*}$ & 52 & 1,580 & 1,862 & 84.9 \\
Sutherland & 51 & 3,066 & 3,231 & 94.8 \\
\hline Total & 127 & 7,571 & 8,577 & 88.3 \\
\hline
\end{tabular}

* Kindergarten starters only. This survey, however, did assess rates for individual immunisations as follows: all of DTP and OPV $(98.8 \%)$; MMR or MM $(95.3 \%)$; pre-school CDT $(90.9 \%)$.

TABLE 11

1992 CENSUS RESULTS FOR KINDERGARTEN STARTERS IN THE SOUTHERN SYDNEY AREA

\begin{tabular}{|lrrrr|}
\hline District & $\begin{array}{r}\text { No. No. children } \\
\text { schools } \\
\text { surveyed }\end{array}$ & $\begin{array}{c}\text { No. } \\
\text { summunised }\end{array}$ & $\begin{array}{c}\text { Proportion } \\
\text { surveyed } \\
\text { fully }\end{array}$ \\
\hline Canterbury & - & 1,203 & 1,448 & 83.1 \\
St George & 51 & 1,580 & 1,862 & 84.9 \\
Sutherland & - & 2,439 & 2,581 & 94.8 \\
\hline Total & - & 5,222 & 5,991 & 87.2 \\
\hline
\end{tabular}

\section{TABLE 12}

1992 CENSUS RESULTS FOR INFANT SCHOOL STARTERS IN THE CENTRAL SYDNEY AREA

\begin{tabular}{|lrr|}
\hline Variable & $\begin{array}{r}\text { Kindergarten } \\
\text { starters }\end{array}$ & $\begin{array}{r}\text { All school } \\
\text { starters }\end{array}$ \\
\hline $\begin{array}{l}\text { No. of schools surveyed } \\
\text { No. children fully }\end{array}$ & - & $50^{*}$ \\
immunised & 626 & 1,028 \\
$\begin{array}{l}\text { No. children not fully } \\
\text { immunised }\end{array}$ & 161 & 293 \\
$\begin{array}{l}\text { No. children with missing } \\
\text { information }\end{array}$ & 116 & 738 \\
$\begin{array}{l}\text { No. children surveyed } \\
\text { Proportion of children }\end{array}$ & 903 & 2,059 \\
$\begin{array}{l}\text { with missing information } \\
\text { Minimum proportion } \\
\text { fully immunised }\end{array}$ & $12.8 \%$ & $35.8 \%$ \\
$\begin{array}{l}\text { Maximum proportion } \\
\text { fully immunised }\end{array}$ & $69.3 \%$ & $49.9 \%$ \\
$\begin{array}{l}\text { Estimated proportion } \\
\text { fully immunised }\end{array}$ & $82.2 \%$ & $85.8 \%$ \\
\hline
\end{tabular}

* Data from 12 schools excluded due to missing information. \# Proportions among known groups extrapolated to those with missing

\section{DISCUSSION}

The high immunisation rates in the Sutherland district of Southern Sydney accord with the low rates of childhood infectious diseases reported from this district to the PHU. Higher rates of these diseases were reported to the PHU from the St George and Canterbury districts of Southern, as would be expected by their lower immunisation rates. The CHNs who collected data from Canterbury asked that these data be regarded with caution as the high number of parents from non-English speaking backgrounds made much of the data unreliable. They believed immunisation 


\section{NeWS AND COMMENT}

\section{NSW HEALTH OUTCOMES PROGRAM FUNDED PROJECTS}

The NSW Health Department invites proposals for

funding for projects which show how an outcome-oriented approach to the planning, implementation and evaluation of public health and clinical services can produce measurable improvements in health outcomes.

In 1992-93 the Department funded health outcomes projects in cardiovascular disease, diabetes, critical care, injury, tuberculosis, immunisation, Aboriginal health, information system development and pregnancy outcomes. While these priorities remain, the Department seeks proposals in other areas, especially mental health, aged care and community health.

Proposals which bring clinicians, managers, consumers and public health professionals together to identify priority indicators and plan the use of appropriate indicator information are particularly sought. Proposals for workshops to identify minimum datasets and action plans to implement outcome-oriented approaches are encouraged.

Projects to be funded in 1993-94 should cover one or more of the following:
development of clinical data systems with the
potential to produce standardised outcome information throughout NSW by 1995 ; application of outcome and/or cost-effectiveness
information to improve health service provision; and development and application of methods for outcome evaluation of health technologies, procedures or services.

Preference will be given to projects which:

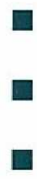

build on existing work in the development of outcome indicators;

provide information to health outcomes councils in Area or District Health Services; promote collaboration among different sectors of the health system; e.g. public health and clinical services;
- involve consumers in the evaluation of health outcomes and the use of outcome data in decision making;

- show evidence of consultation and collaboration among clinicians, health service administrators, public health specialists and consumers; and - include the development and/or implementation of standardised information systems, procedures and practices suitable for ready adoption in multiple sites in NSW.

Projects must be completed by January 1995 . To obtain a copy of an application kit, telephone (02) 3919219 , or send a request by facsimile to (02) 3919232 . Closing date for applications is December 20, 1993.

Inquiries may be directed to Dr George Rubin, Director, Epidemiology and Health Services Evaluation Branch, telephone (02) 3919191.

\section{BEE STING WARNING}

The NSW Apiarists' Association has issued advice about bee stings. Secretary Fred Benecke has warned that using insect repellants when going near bees will usually ensure a severe stinging, because repellants can make bees aggressive. He also said the way to remove a bee sting is to scrape it off, usually with a fingernail. The nail slips in under the venom sack and removes it without allowing any more venom into the puncture made by the barbed sting. The affected area should be washed, as venom on the skin may attract other bees.

\section{REHABILITATION AND PAIN MANAGEMENT CONGRESS}

The International Federation of Physical Medicine and Rehabilitation will hold its 12 th world congress from March 27 to 31 in Sydney, in conjunction with the annual scientific meetings of the Australasian Faculty of Rehabilitation Medicine (RCAP), the Australian Pain Society and the New Zealand Pain Society. For information about the congress contact the IFPMR Secretariat, PO Box 629, Willoughby NSW 2068. Telephone (02) 4178525 ; Facsimile (02) 4178513.

\section{Immunisation census}

Continued from page 130

rates may be much lower in children of these families. The PHU's experience supports this view after a large outbreak of measles occurred in this district in November-December 1992, during which most children seen did not have records of immunisation against measles.

While much information obtained from Central Sydney is missing, useful statistics were able to be derived: the maximum and estimated proportions of children who were fully immunised. The maximum rates are much lower than the results obtained for Southern Sydney and low by Australian standards. The estimated rates are even lower and, if close to the true values, reveal a situation which is clearly inadequate. The PHU experience with measles outbreaks in the Area (February-March 1991, April 1992, December-January 1993) and the high number of measles cases reported in the Area for 1992 (54) also suggest that immunisation rates are low.

Introduction of compulsory documentation of immunisation in 1994 will not only facilitate accurate assessment of immunisation rates but will also encourage parents to regard childhood immunisations as an important issue.

\section{Conclusion}

Based on parental recall, rates of children fully immunised at school entry in 1992 were found by this census to be 88.3 per cent in the Southern Sydney Area and were estimated at 77.8 per cent in the Central Sydney Area. The central Sydney rates had to be estimated due to substantial amounts of missing data (the estimate is not highly reliable). In addition, there was concern about the accuracy of data based on parental recall.

\section{Acknowledgement}

We thank the child health nurses of Central and Southern Sydney Areas for providing the data for this census. 